\title{
Rod-cone interactions and analysis of retinal disease
}

\author{
G B ARDEN AND C R HOGG
}

From the Department of Clinical Ophthalmology, Institute of Ophthalmology, Judd Street, London, and the Electrodiagnostic Department, Moorfields Eye Hospital, City Road, London

SUMmaRY Cone flicker threshold rises as the rods dark adapt, though the cone threshold to continuous light remains constant. The rise is normally about $1 \log$ unit, but in certain patients who complain of night blindness it may be as great as $2.5 \mathrm{log}$ units. In these persons the kinetics of the rod-cone interaction are those of the recovery of rod sensitivity. The rods impose a low-pass filter on the cones. This effect is absent in congenital nyctalopia and $\mathrm{X}$-linked retinoschisis. We suggest that cone flicker is maintained through a feedback system involving horizontal cells, and when the rod dark current returns in dark adaptation this feedback is altered. Rod cone interaction thus tests rod dark current, and cases of abnormal interaction in patients with retinitis pigmentosa occur, which indicate that the transduction mechanism and the membrane dark current may be differentially affected.

There have been several attempts to use psychophysical methods to localise disease conditions to given retinal layers, notably by Enoch and his collaborators,' but the methods involved have often been complex and time consuming and have made considerable demands on the patient. However, recently Goldberg et al. ${ }^{2}$ have described an increase in the cone flicker threshold which occurs as the rods dark adapt. This inhibition of cones by rods has been known for many years, ${ }^{3}$ but in the form described the phenomenon is robust, simple to elicit, and is familiar to clinicians. The interaction is developed at a specific retinal site. It therefore promises to be of considerable use in the investigation of retinal disease. Recently properties of the rod-cone interaction have been described. ${ }^{40}$

This paper presents additional findings which help to define the nature and the site of the interaction. Equipment for a clinical test is described together with observations which show that the interaction is abnormal in a number of clinical conditions. These provide strong evidence about the site of the interaction, and suggest that study of the phenomenon will increase our understanding of various causes of night blindness.

\section{Material and methods}

EQUIPMENT

Most of the initial work was done with the computer-

Correspondence to Professor G B Arden, Institute of Ophthalmology, Judd Street, London WC1H 9QS. ised light-emitting diode (LED) perimeter described by Ernst et al. ${ }^{\prime}$ This placed $1^{\circ}$ green or red spots of light anywhere in the visual field. In the present experiments a site $10^{\circ}$ nasally was usually examined. Additional experiments were performed with similar equipment but manually controlled. In one version the filtered LED (light output centred at $660 \mathrm{~nm}$ ) was attached to one end of a flexible light-pipe, the other end of which was inserted through a hole in a piece of white card, which could be illuminated to produce a dim blue surround. The $(460 \mathrm{~nm})$ light which was used to illuminate the surround was provided by a Grass PS22C stroboscope fitted with neutral and colour filters. ${ }^{89}$ The mean light output was altered by changing the flash rate between 40 and 60 pulses per second (pps) so that, with all the filters in place, the surround was at the rod absolute detection threshold. Under the conditions of the experiments the blue light appeared continuous.

The final equipment utilised both blue and red LEDs. These were driven by a pulse technique. The advantages of this drive, which has been developed from devices previously described in detail, ${ }^{710}$ are that linear output can be maintained over six decades of intensity: circuits which depend on variable current driving ${ }^{8}$ provide linear output over a more limited range of intensities. In addition the pulse driving circuit can provide various stimulus waveforms. Pulses, sine waves, increments, and decrements of light intensity can readily be achieved, and various spatial outputs, for example discs, annuli, chequerboards, etc., are easily realisable. In the present experiments only uniform patches of light were used, and usually flicker was produced by abruptly turning the stimulus light on and off. However, the luminance could easily be made to change in a sinusoidal fashion, and then the modulation depth of the stimulus, defined as $\left(I_{\max }-I_{\min }\right) /\left(I_{\max }+I_{\min }\right)$, could be varied, so that the modulation thresholds could be determined for every temporal frequency at the same mean level of illumination. 


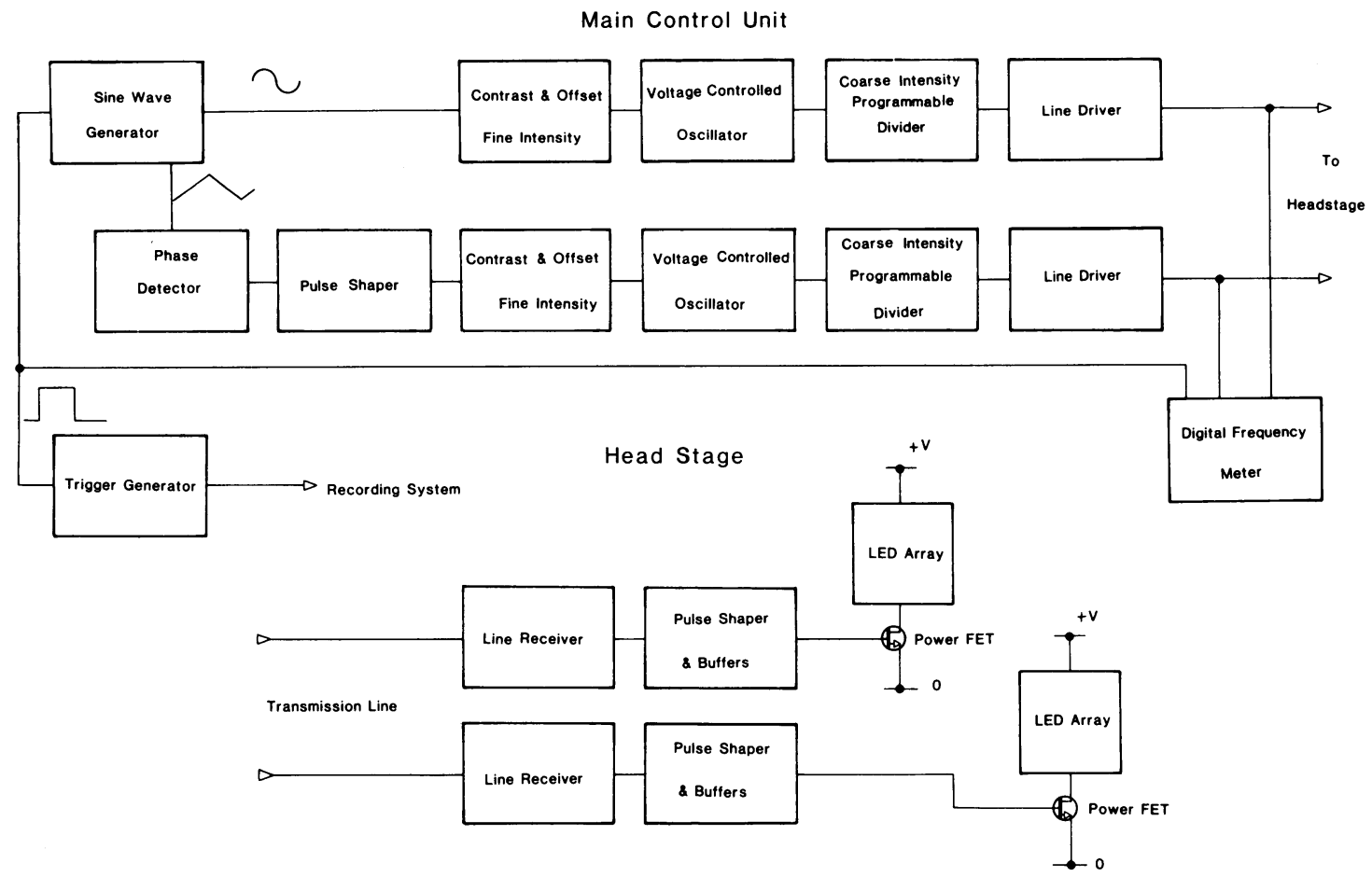

Fig. 1 Block diagram of the stimulus generator. One channel produces sinewave light outputs from 0.6 to $90 \mathrm{~Hz}$. The modulation depth is continuously variable from better than $99.99 \%$ (for all except the weakest stimuli) to $0.1 \%$. The mean light output can be continuously varied over a range of 1000:1, and in addition precise divisions of $2,5,10 \ldots 10^{5}$ are available. The second channel produces pulses of light, from $0 \cdot 1$ to $100 \mathrm{~ms}$, at the same repetition rate as the sinewave. The pulses are phaselocked to the sinewave, and a continuous adjustment of $\pm 176^{\circ}$ is possible. For further information see text.

The block diagram and components are shown in Fig. 1. The waveform generator (Intersil 8038) provides sine, square, and triangle outputs. In the configuration shown the last is fed to a variable trigger point comparator, which thus acts as a phase detector (TLO81CP). The sine wave or pulse outputs are offset and attenuated to provide contrast and mean level controls, using standard operational amplifier techniques. The controls are 10-turn potentionmeters, allowing settings to 1 part in 1000 . It would be easy to provide for digital control at this stage if the equipment were to be connected to a computer. The signals alter the frequency of voltage controlled oscillators (VCOs). In the equipment, these are basically similar to the ones described by Faulkner, ${ }^{710}$ and for an input of $0-2.5 \mathrm{~V}$ provide an output from $100 \mathrm{~Hz}$ to $>5 \mathrm{MHz}$, with a linearity of $>1 \%$. This is a discrete system, but a recently announced single package hybrid (Advanced Modular Concepts, 3800 series) exceeds this specification. The pulses from the VCOs are fed to edge sensitive counters (79LS390), and here divisions of 1,2,5,10 . 10 $10^{5}$ are made for coarse control of light intensity. The pulses $(50 \%$ duty cycle) are now fed to RS 422 line drivers, so the control equipment can be remote from the light sources. A simple digital meter inserted at this point in the circuit measures the stimulus repetition rate and also the light intensity, since this is directly proportional to the pulse frequency. Standard TTL pulse shapers and buffers are employed to produce $100 \mathrm{~ns}$ pulses. These drive power FETs, used as current sinks, which are sufficiently fast to pulse the necessary current and voltage through the LEDs. For all light outputs the current per pulse is constant, thus ensuring linearity. The LEDs are connected in series, and the number used depends on the supply voltage available and the forward voltage drop per LED: this varies with the type used. The peak current pulse used is very much greater than the maximum continuous forward current for the LED, and therefore high light outputs can be achieved, and of course these remain constant for the lifetime of the LED, which is much greater than for incandescent lamps or flash tubes.

In general it is possible to make the drive in such a way that various LED arrays may be plugged into the same unit, allowing for rapid interchange of light sources. The system is easily constructed, since integrated circuits are available for most components, with minimal external circuitry. Component costs are less than for a stroboscope, even for the complex version shown in Fig. 1. Further details are available from the authors. Red, orange, yellow, green, and blue LEDs are now available which will readily provide sufficient light for most physiological purposes, including electroretinography. The only disadvantage is the cost of blue LEDs (US\$6 each).

\section{SUBJECTS AND PATIENTS}

The authors and associated workers from the clinic acted as subjects. Other results were obtained on volunteers from the department who were au fait with the research and therefore could give informed consent. Other work was done in the course of normal dark adaptometry on patients who were referred for investigation of their eye condition. All observations were made after dilation of the pupil with $1 \%$ mydrilate. All subjects and patients had $6 / 6$ 
Table 1 Dark adaptation in normal subjects

\begin{tabular}{|c|c|c|c|c|c|c|c|c|c|}
\hline \multirow[t]{2}{*}{ No. } & \multirow[t]{2}{*}{ Age } & \multicolumn{3}{|l|}{$\begin{array}{l}\text { Thresholds* } \\
\text { at } 10^{\prime}\end{array}$} & \multicolumn{3}{|l|}{$\begin{array}{l}\text { Thresholds } \\
\text { at } 30^{\prime}\end{array}$} & \multicolumn{2}{|l|}{$\begin{array}{l}\text { Change from } \\
10-30^{\prime}\end{array}$} \\
\hline & & Green & Red & Green-red & Green & Red & Green-red & Green & Red \\
\hline 9 & $32 \cdot 5 \pm 16(16-70)$ & $-0.32 \pm 0.20$ & $0.41 \pm 0.51$ & $0 \cdot 58 \pm 0 \cdot 50$ & $-2 \cdot 23 \pm 0 \cdot 50$ & $1 \cdot 12 \pm 0.55$ & $-2 \cdot 12 \pm 1 \cdot 02$ & $-1 \cdot 91 \pm 0 \cdot 60$ & $0.71 \pm 0 \cdot 30$ \\
\hline
\end{tabular}

${ }^{*}$ Light intensities expressed as $\log$ candelas $\mathrm{m}^{-2}$. Mean values and standard deviations are given (equivalent to 3 SEMs). The differences between green and red thresholds, and the change in threshold with time in the dark, are means of the individual values.

vision after spectacle correction, and had no visible fundus changes or complaints apart from the specific problems mentioned in the text.

Subjects and patients were light adapted either by using a photographic flash unit connected to a rigid light pipe, or by a tungsten-halide bulb viewed through a Fresnel lens system in maxwellian view. In both cases large areas of the retina $(>1 \mathrm{sr})$ were illuminated by more than $7.5 \log \operatorname{td} \mathrm{s}^{1}$, which is sufficient to bleach almost all the rhodopsin."

Psychophysical techniques. In most experiments the method of ascending limits was used, with a

Fig. 2 Dark adaptation curves in a subject with an exaggerated rodcone interaction. The test stimuli were placed $10^{\circ}$ nasally, subtended $1^{\circ}$ at the eye, and were produced by filtered green and red LEDs. The preadaptation was by an intense flash which bleached most of the retinal rhodopsin. Each point is the average of two determinations of visual threshold. A computer caused a steady increase in the intensity of the test light, and recorded the intensity when the patient responded by pressing a button. Each run began at a randomly selected subthreshold intensity. The computer continued to test the subject until the standard deviation of the threshold fell below $0.2 \mathrm{LU}$. Green threshold and red flicker threshold determinations alternated. Note that the red flicker threshold begins to rise at about the time of the rod break in the green threshold curve. The dashed line is the reciprocal of the rod threshold. The exact threshold levels and the magnitude of the change in rod threshold vary across the retina, but it is evident that there is a close correspondence between the kinetics of rod dark adaptation and the rise in cone flicker threshold to red light. computer providing a standard rate of increase of light intensity. ' In a few cases this was checked by using a forced choice staircase method, with ascending and descending intensities, and the threshold was then taken as the point where the probability of correct positive and negative responses was equal. In static conditions the results obtained by the two methods were similar, but the forced choice method was laborious and not suited to measurement of changing thresholds.

\section{Results}

Dark adaptation curves measured with red light flashes showed a rapid increase of cone sensitivity, which was essentially complete after three minutes. ${ }^{34711}$ After about 20 minutes rod dark adaptation might have progressed so far that even far red light was perceived best by rods, and a further slight decrease in threshold might occur. ${ }^{7}$ Whether this is seen depends upon whether the red test flash sub-

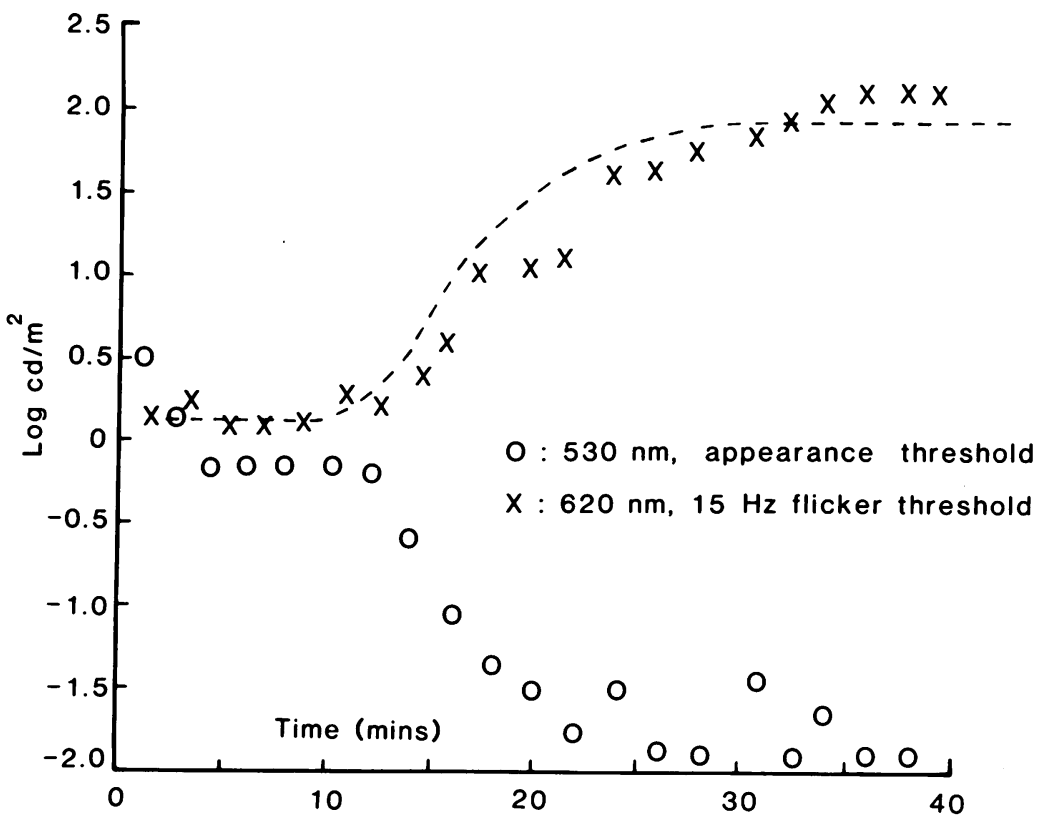


$\log 1$
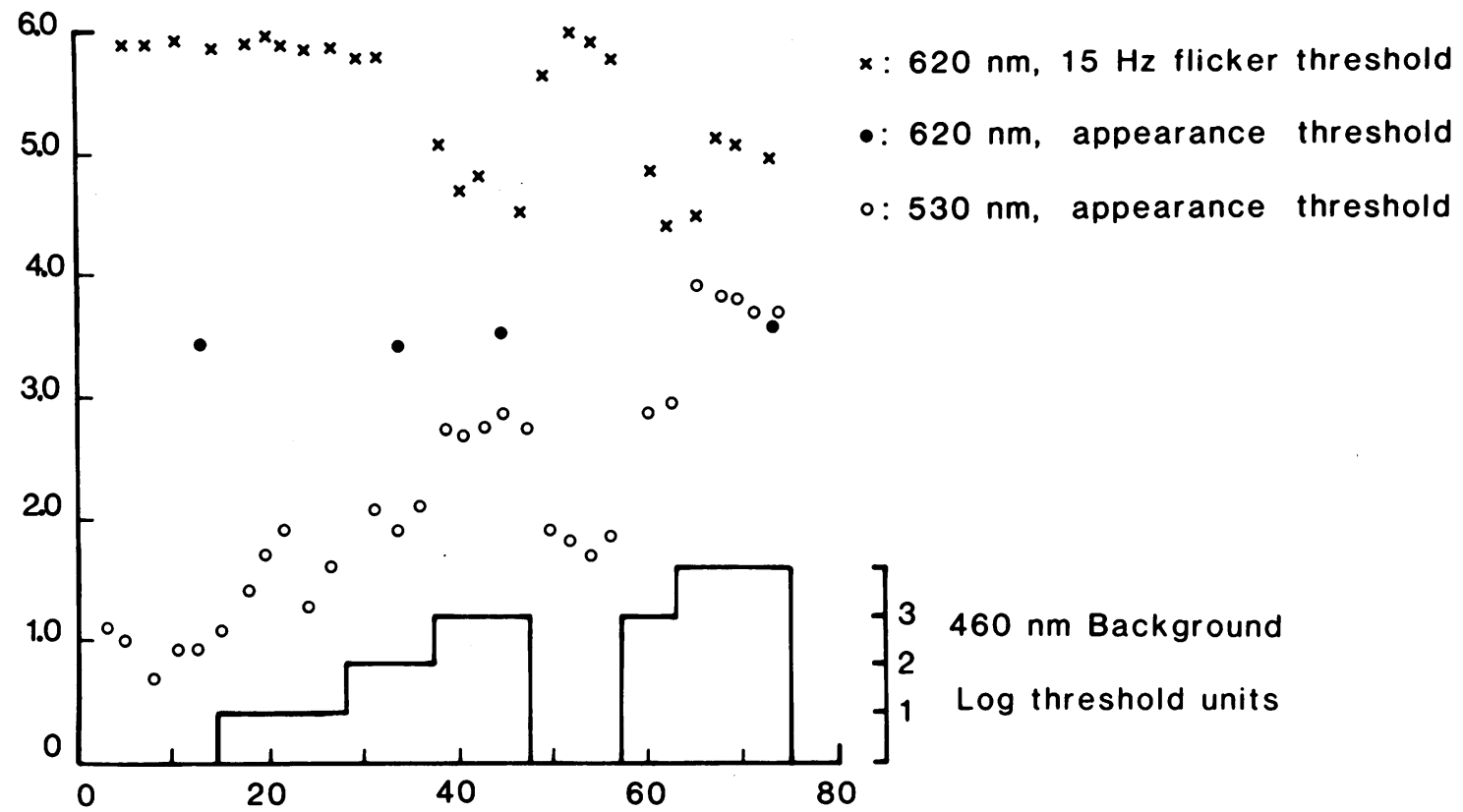

Time (mins)

Fig. 3 Increment thresholds in a second subject with an exaggerated rod-cone interaction. The background was a $10^{\circ}$ disc illuminated by $460 \mathrm{~nm}$ light (see 'Material and methods'). The subject dark adapted, and then visual threshold was determined for the background. The right hand ordinate gives the intensity in multiples of this threshold. Note that the threshold for detecting the red light (at $15 \mathrm{~Hz}$, the sensation evoked is of a continuous constant luminosity) is unchanged by the rod background until, with four log units of filter removed, the threshold rises slightly. In contrast, the flicker threshold for red light drops when the background is increased. Other conditions similar to those for Fig. 2.

tends a large area, and is placed in a region of high rod density. However, if the stimulus is a $15 \mathrm{~Hz}$ square wave flicker, and the subject is asked to report not when he sees the light but when he sees it flicker, a very different result occurs. From about the 10th to the 25th min after the beginning of dark adaptation the flicker threshold rises, by over half a log unit. ${ }^{2}$ Table 1 gives the range for our 'normal' subjects. The slow time course of this change and the fact that it began almost at the moment of the rod-cone break suggests very strongly that the rod dark adaptation was causing the loss of sensitivity of cones.

In some persons the rise is much greater. We have found three of these, and all complained of difficulty with night vision, specifically in driving at night. Fig. 2 shows the result obtained in a patient aged 30 , who had been seen for 10 years. No abnormality had ever been detected, but the patient, who is medically qualified, was positive he and other members of his family were visually impaired in dim light conditions. Since cone and rod thresholds were normal by a Goldmann-Weekers adaptometer, a possible psychogenic disturbance had been discussed. How- ever, the threshold for detecting cone flicker rises by about $2.5 \mathrm{log}$ units as the rods dark adapt, and because the effect is so large its kinetics are easy to study. The dashed curve in Fig. 2 gives the reciprocal of rod threshold, and it can be seen there is good agreement between it and the cone threshold data. Similar results have been found on other subjects (Fig. 6). One of these, a laboratory technician aged 39 , volunteered that she had difficulty in driving at night and in seeing kerb markings. Another of our colleagues, hearing of these results, suggested he should be tested, and he also had a large rise of flicker threshold. However, another subject who claimed he had the same disability had a threshold rise of only $0.6 \log$ unit.

The appearance of the cone inhibition can be reversed by using a background which stimulates only rods. Fig. 3 shows this, again on a subject with an exaggerated effect. It can be seen that 3 log units of background were required before the cone flicker threshold abruptly fell. At visual threshold only a small fraction of the rods-perhaps one in a hundred -absorbed a quantum of light per second. Thus the 


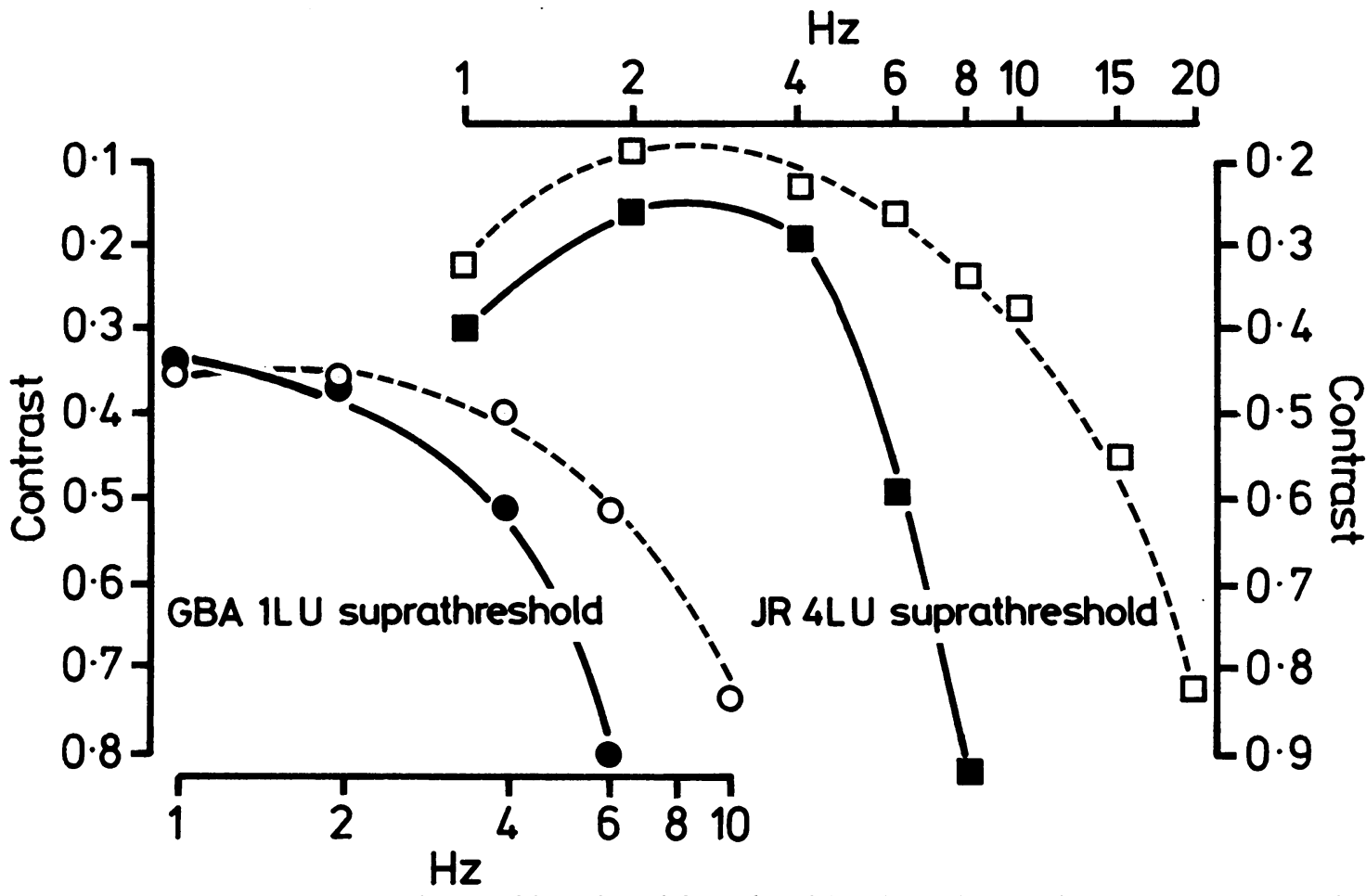

Fig. 4 Modulation threshold curves for one of the authors (left panel) and the subject whose results are shown in Fig. 3 (right panel). In the former case the red test light was 1 log unit above the threshold for detection in darkness. For the latter the intensity was 4 log units. In both cases the backgrounds were 3 log units above the threshold of the rods and thus just below threshold for red cones. Closed symbols without, and open symbols with, a background. Note that the background does not affect modulation sensitivity for the $1 \mathrm{~Hz}$ sinewave red test, but reduces it for higher temporal frequencies.

illumination which causes the fall in cone flicker threshold is one where all the rods are continuously stimulated, but the rod dark current is reduced but not abolished. ${ }^{12} 13$ The rapid increase of the cone threshold when the rod background is turned off is what would be expected under such circumstances. Such a background, while effective in stimulating rods, is still subthreshold for the red cones. Note that 4 log units suprathreshold light was required to increase the cone flash threshold.

The inhibition of the cone signal occured only at higher temporal frequencies. Fig. 4 presents the modulation curves for two subjects, and it can be seen that, while for low frequencies $(1 \mathrm{~Hz})$ the threshold modulation was unaffected by the background, for higher frequencies the effect became progressively greater: Dark adapted rods seemed to interpose a low-pass filter into the cone pathway.

The effect of backgrounds is not critically dependent on the light intensity used in the red test. Fig. 5 shows results obtained when it is set at 1,3 , and 4.3 log units above the $1 \mathrm{~Hz}$ detection threshold. For all these values the effect of the background was to decrease the depth of modulation required to see the flicker. The ability to detect the flicker was much greater for the stimulus which was $3 \mathrm{LU}$ above threshold, but the further increase caused little change either in the dark adapted condition or in the presence of a background. Thus the effect of the background cannot (within these limits) be mimicked by increasing the intensity of the test light. These observations are incompatible with the idea that the effect is somehow spurious and produced by subliminal stimulation of the cones by the rod stimulus.

Another observation which shows that a novel form of interaction is occuring is that the rise of flicker threshold was seen only if the red test field was relatively small: the rise of approximately $2 \mathrm{LU}$ shown in Fig. 6 was totally absent if a $50^{\circ}$ field was used as a test target (Fig. 6).

ROD-CONE INTERACTION IN PATIENTS WITH ABSENCE OF ROD B WAVES

The site of the interaction between the rod and cone pathway can be investigated by utilising clinical pathology. In nyctalopia there is a failure of synaptic 

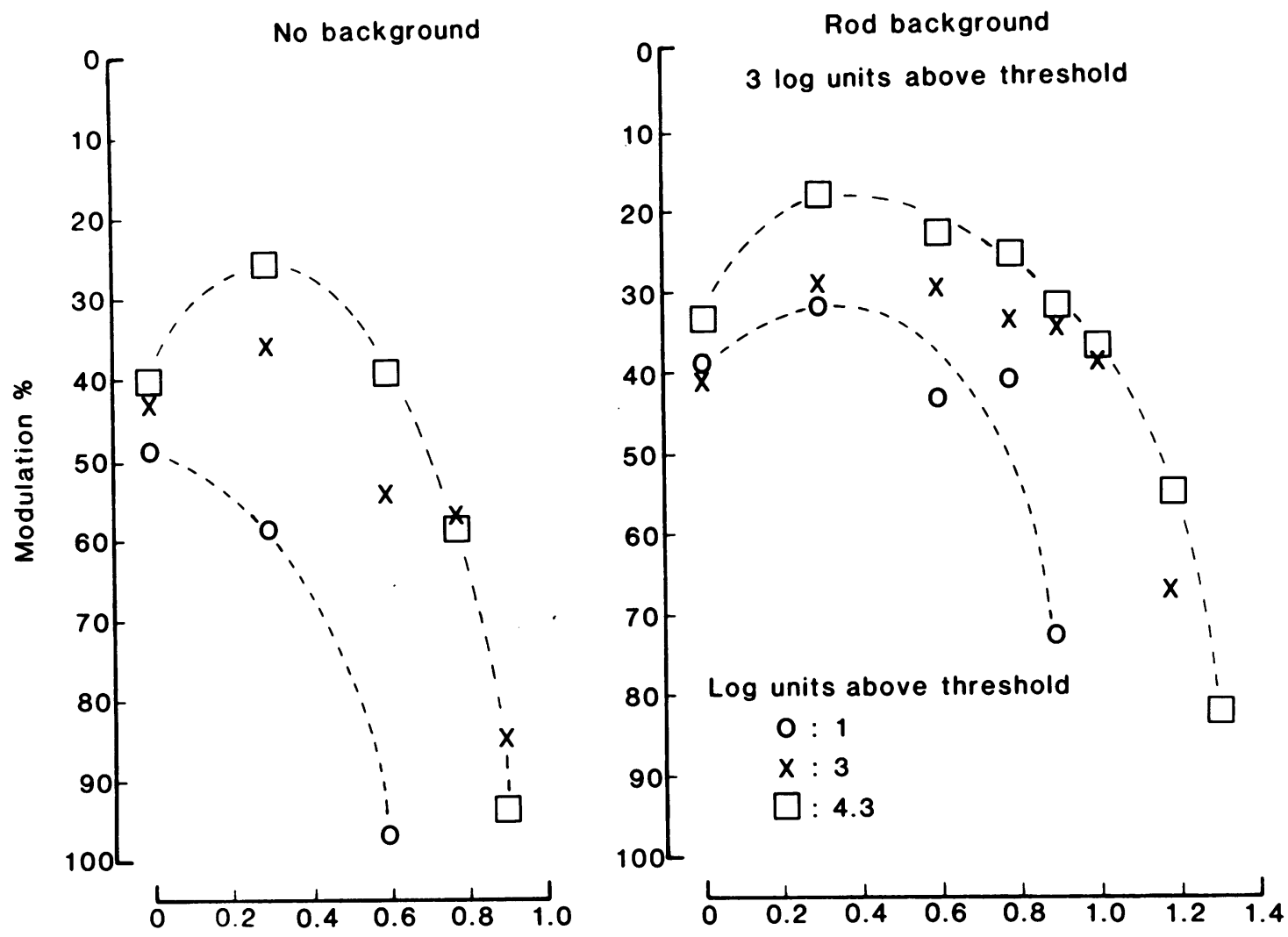

\section{Log Frequency $(\mathrm{Hz})$}

Fig. 5 Modulation thresholds as a function of test light intensity, without a background (left) and with a background (right). Note that for test lights 3 and 4.3 log units above the detection threshold the high frequency modulation thresholds are not greatly different, but there are large effects of the $460 \mathrm{~nm}$ background, which is 3 log units above the rod threshold.

transmission by rods, though rhodopsin is present, and there is electroretinographic evidence that only the rod receptor potential is developed." 14 is Consequently, if the rod-cone interaction occurs at a site which preceeds the development of the $b$ wave, it should be developed in nyctalopes. Fig. 1 in Arden and Hogg's paper ${ }^{4}$ shows that in one patient this is not the case. Various forms of nyctalopia have been described ${ }^{111417}$ and our patients fall into two groups - those with and those without elevation of the cone flicker threshold. Table 2 shows the thresholds after 5 minutes and 20-30 minutes of dark adaptation in this group. All the patients had classical electroretinograms, consisting of rod PIII and some cone b wave. The mean rise in the flicker threshold is $-0.025 \mathrm{LU}$.

The appearance of an isolated rod PIII also occurs in some cases of X-linked retinoschisis. ${ }^{15} 18$ In young patients vision is well preserved, and schisis at the posterior pole is patchy, so large cysts such have been reported in the literature are not formed. The fundus photograph of the eye is shown in Fig. 7. Dark adaptation thresholds are normal or moderately elevated. In cases such as these (see the caption to fig. 8 for further details) the cone flicker threshold does not rise during rod dark adaptation (Fig. 8). However, in one family, the results are variable, and this is not surprising, for so too is the degree of schisis. The cases we have seen differ from the nyctalopes in one respect, that rods continue to function though there may be an elevation of the dark adapted threshold.

\section{ROD-CONE INTERACTION IN RETINITIS} PIGMENTOSA

In some cases where there is no detectable rod function (type 1, see Arden et al.," Massof and Finkelstein ${ }^{19}$ ) rod-cone interaction has not been seen, though cone threshold was not significantly elevated. In one patient with type II disease and well preserved rod function the effect was present, though reduced (Fig. 9). In another patient with type II disease there 


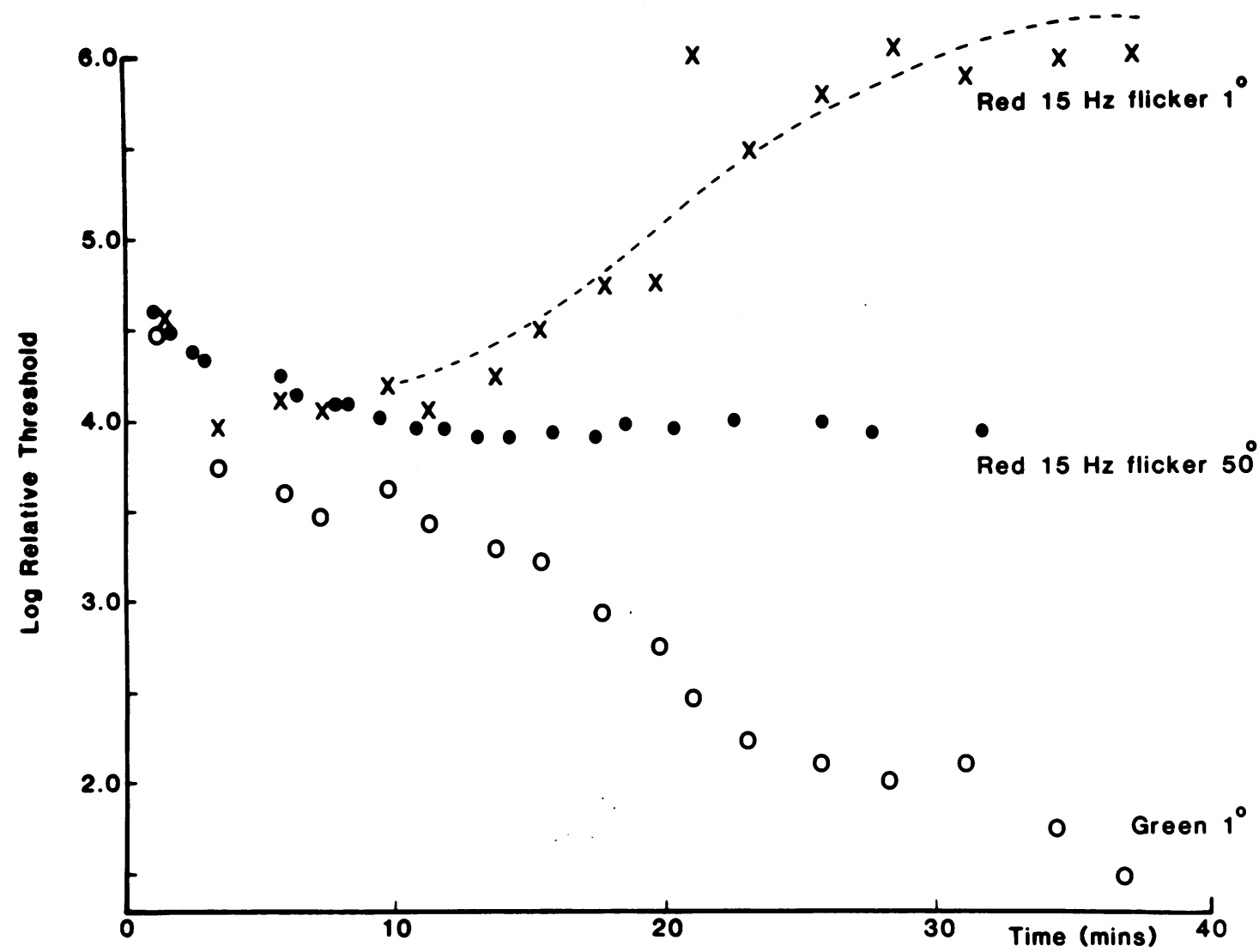

Fig. 6 Dark adaptation curves from a subject with an exaggerated rod cone interaction. Conditions for the $1^{\circ}$ green and red fields are similar to those in Fig. 2. Note the cone data also agree with the reciprocal of the rod threshold (dashed curve). However, when the red flickering light subtended c. $50^{\circ}$, the interaction is absent. The test stimulus was made by backprojecting red LEDs on to an opal screen, which also carried another small LED for fixation. The test spot subtended $6 \mathrm{~cm}$ and was placed $6 \mathrm{~cm}$ from the eye.

was slowed dark adaptation, ${ }^{20}$ and a normal sized increase in the cone flicker threshold occurred at a time when the patient's rods were very insensitive. No further change occurred as they gradually recovered (Fig. 10) and threshold for green light fell to nearly normal limits.

\section{Discussion}

The rod-cone interaction described ${ }^{2}$ is a very robust phenomenon, and can easily be measured by a simple modification of most dark adaptometers. It is consequently a practical clinical test. Patients easily comprehend the idea of distinguishing between the appearance of a light and the development of a sensation of flicker. The threshold for detection of a red light flickering at $15 \mathrm{~Hz}$ is little different from that of a non-flickering red light, and during the early part of the cone plateau the thresholds for detection and recognition of flicker in most patients are nearly the same. Consequently, even if the adaptometer is modified so that the red test spot always flickers, there is no loss in terms of the information available, and there are the gains described above, in terms of diagnosis of complaints of loss of night vision.

One of the new findings made in the course of the investigation is that there are persons in whom the rod cone interaction is exaggerated, and that these persons either present with the complaint or volunteer the information that they have difficulty in seeing at night. Although in many cases where no retinal cause can be found subjective nyctalopia may be due to aging processes, which reduce retinal illumination or cause glare, or to night myopia, there remains a core of patients in whom, as demonstrated above, dark adapted rods seem to cause gross inhibition of the sensation caused by small, rapidly changing objects. The task which one would predict would be 


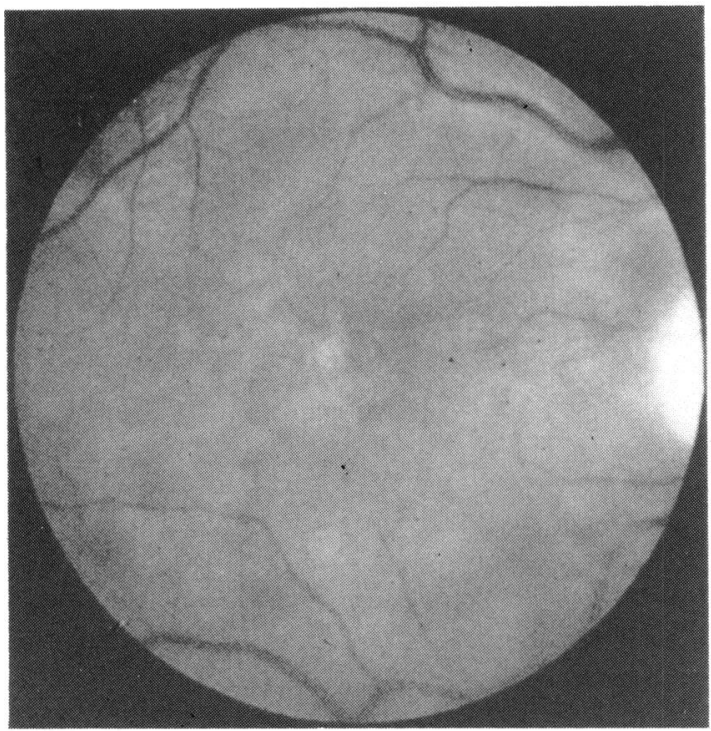

Fig. 7A

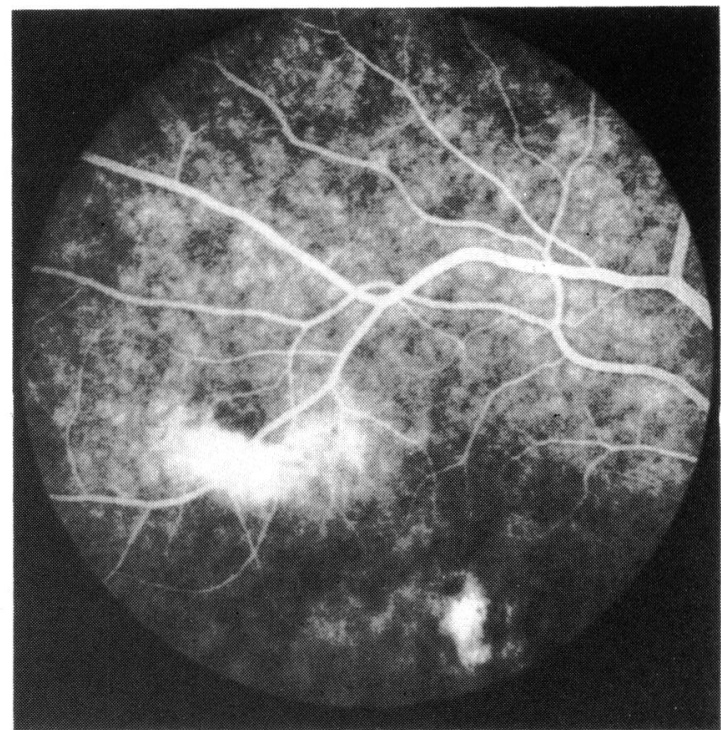

Fig. 7B

Fig. 7 A: Fundus photograph of patient with X-linked retinoschisis, case 13011, whose ERGs and dark adaptation curves are shown in Fig. 8. B: Early phase fluorescein angiogram of peripheral retina in same subject.

difficult for such persons is night driving, and this is the presenting complaint. It is therefore plausible that abnormally active rod-cone interaction can be a hitherto unsuspected cause for referral to an ophthalmologist. In the absence of other signs and symptoms, and before the demonstration that all people such as those whose results are shown in Fig. 2-6 have actual visual disability, it is premature to suggest that the test has uncovered a new disease.
However, it is possible that in one of our patients, the condition is familial.

MECHANISM OF ROD-CONE INTERACTION

Depending on the cause of the interaction, the test can shed light on the pathophysiology of disease, and for this reason our first investigations have been directed to this end. In the mammalian retina there are numerous gap junctions between rods and

Table 2

\begin{tabular}{|c|c|c|c|c|c|c|c|c|c|}
\hline \multirow{3}{*}{$\begin{array}{l}\text { Patient } \\
\text { No. }\end{array}$} & \multirow[t]{3}{*}{ Age } & \multirow[t]{3}{*}{$V A$} & \multirow[t]{3}{*}{$E O G$} & \multirow[t]{3}{*}{$E R G$} & \multicolumn{4}{|c|}{ Thresholds* } & \multirow{3}{*}{$\begin{array}{l}\text { Rod-cone } \\
\text { - interaction } \dagger\end{array}$} \\
\hline & & & & & \multicolumn{2}{|c|}{ At cone plateau } & \multicolumn{2}{|c|}{ Final value } & \\
\hline & & & & & Red & Green & Red & Green & \\
\hline \multicolumn{10}{|c|}{ Summary of data on patients with X-linked retinoschisis } \\
\hline 13011 & 22 & $6 / 6$ & 117 & - ve & $0 \cdot 35$ & $0 \cdot 35$ & $0 \cdot 1$ & $-1 \cdot 70$ & -0.25 \\
\hline 11806 & 46 & $6 / 60$ & 178 & subnormal & 0.00 & - & 0.5 & - & 0.5 \\
\hline 13565 & 59 & $6 / 60$ & - & -ve & 0.45 & 0.5 & 0.3 & -1.43 & $-0 \cdot 15$ \\
\hline 13331 & 48 & $6 / 36$ & - & -ve & $0 \cdot 15$ & -0.25 & 0.05 & $-1 \cdot 70$ & $-0 \cdot 10$ \\
\hline 13493 & 10 & $6 / 18$ & 200 & $\begin{array}{l}\text { reduced } \\
\text { b waves }\end{array}$ & $0 \cdot 10$ & -0.65 & 0.80 & $-2 \cdot 05$ & 0.70 \\
\hline 13494 & 6 & $6 / 6$ & 240 & $\begin{array}{l}\text { reduced } \\
\text { b waves }\end{array}$ & $-0 \cdot 25$ & -0.25 & -0.40 & $-2 \cdot 02$ & $-0 \cdot 15$ \\
\hline \multicolumn{10}{|c|}{ Summary of data on patients with stationary night blindness $\ddagger$} \\
\hline 13500 & 36 & $6 / 6$ & - & -ve & 0.45 & 0.80 & 0.35 & 0.60 & $-0 \cdot 10$ \\
\hline 14085 & 22 & $6 / 12$ & - & -ve & $2 \cdot 10$ & 0.08 & $2 \cdot 10$ & -0.40 & 0.0 \\
\hline
\end{tabular}

*Threshold values in $\log \mathrm{cd} . \mathrm{m}^{-2}$.

†Normal interaction is given a + ve sign.

$¥$ All patients had full fields with no scotomata, no ophthalmoscopic changes in the fundus, a history of nyctalopia for many years, and no evidence on repeated visits of any progressive disorder. 


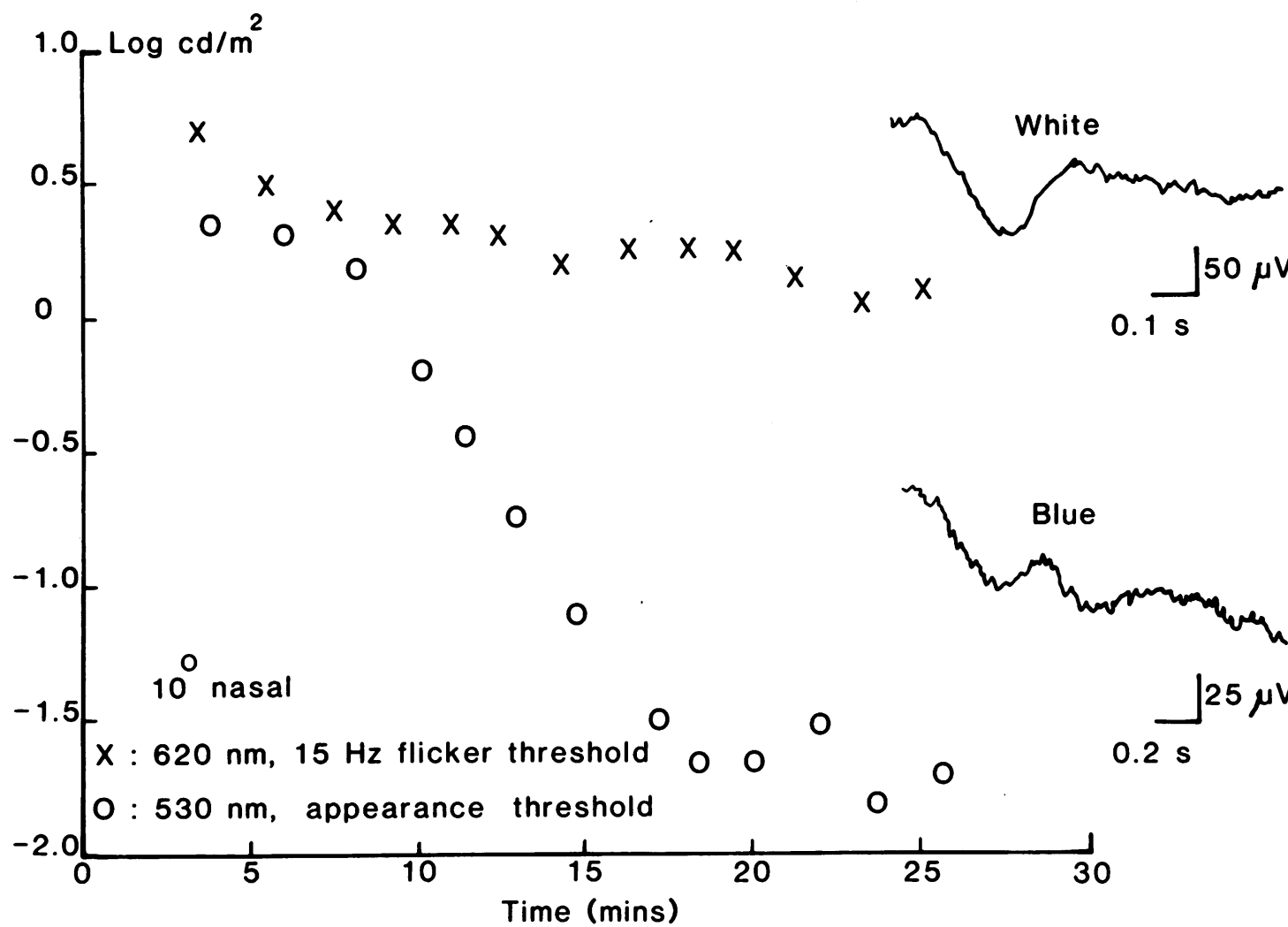

Fig. 8 Dark adaptation curves and ERGs of a patient with X-linked retinoschisis, aged 22. He was first seen aged 8 , with reduced visual acuity, when macular changes were noted. He was seen again in 1983 , with VA 6/36 R and L, with a small right vitreous haemorrhage inferonasally. Macular and perimacular changes were seen, and leakage was shown round the disc and in the periphery on fluorescein angiography. The retina was flat, but 'looked like Cellophane.' The ERG was negative, and the light rise in the electrooculogram (the EOG) was $200 \%$ in each eye. Twelve months later the vitreous haemorrhage had resolved and visual acuity was unchanged. The areas of schisis were discrete and limited to the posterior pole. The white and strong blue ERG stimuli produced the responses shown, with large a waves, and very subnormal $\mathrm{b}$ waves, but the EOG of the $R$ eye had fallen to $116 \%$ The green light rod dark adaptation curves are nearly normal. The flicker thresholds for red light remain constant as the rods dark adapt. The conditions of the test were the same as those for Figs. 2 and 6.

cones, ${ }^{21}$ so that presynaptic interaction is possible. The results with nyctalopia provide good evidence that the interaction is postsynaptic. The absence of the interaction in patients with retinoschisis, who are not night blind, implies that the bipolar cellganglion cell pathway itself cannot mediate the interaction. The finding that the interaction interposes a low pass filter in the cone pathway, but that this effect is absent or reduced when the cone test stimulus has a very large subtense, suggests strongly that the rod interaction occurs via a lateral interaction with a large spatial summation pool, and the earliest site for this to happen is the horizontal cell, which has such characteristics. ${ }^{22-24}$ In mammals horizontal cells are known to form synapses with both rods and cones, ${ }^{212-28}$ and the axon terminations receive predominantly rod inputs. All $S$ potentials recorded contain rod and cone components, but the potentials are additive. The inhibition of cones by rods is not directly explicable from such observations. However, an inhibitory action which is well known involves the feedback to cones ${ }^{12229}$ from horizontal cells. This has been demonstrated only in turtles and amphibia, where intracellular recordings from photoreceptors is possible, but the synaptic appearances in the primate outer plexiform layers suggest a similar organisation. The effect of the feedback is to reduce the cone receptor potential waveform ${ }^{29}$ after a delay, so that the flash evoked response reaches its peak and then suddenly decreases. As expected, this feedback improves the high frequency response of the cone system. ${ }^{3031}$ 


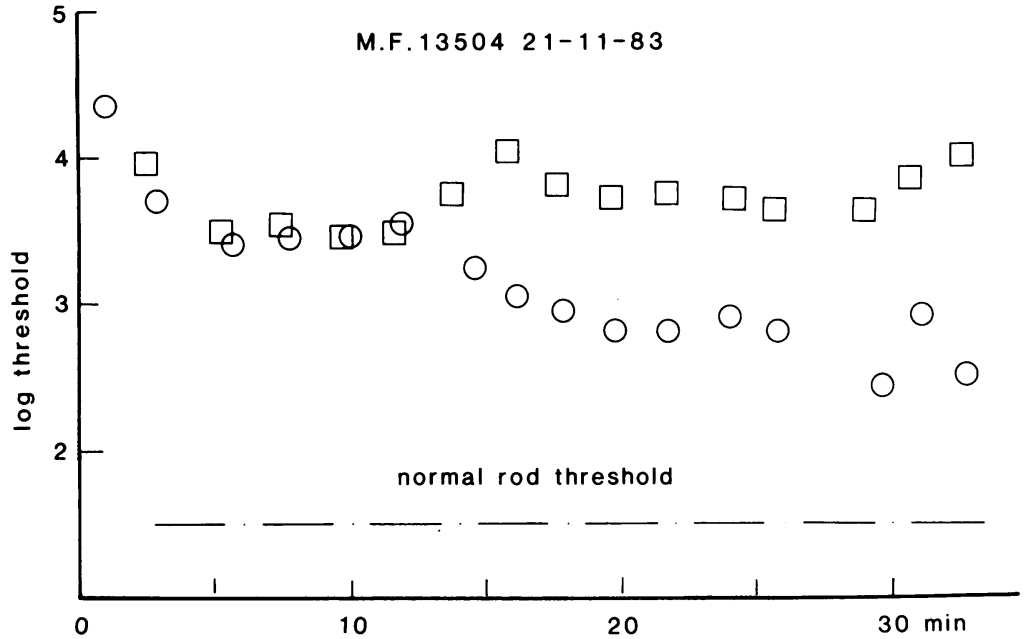

The simplest explanation of the findings described under 'Results' is that late in dark adaptation the cone feedback system becomes relatively inefficient, so that the high frequency responsiveness of the photopic system is decreased. Horizontal cells, like photoreceptors, are depolarised in darkness and are supposed under these conditions to liberate continuously an inhibitory transmitter. Hence when a stimulus hyperpolarises the cones, and the horizontal cell membrane hyperpolarises in turn, there is a small proportional decrease in the concentration of the inhibitory feedback transmitter. When rods hyper-
Fig. 9 Rod cone interaction in a patient with retinitis pigmentosa, aged 70 . The patient's condition was discovered when she went to an optician for reading glasses. The fundi showed extensive pigmentation in the midperipheral zone, much of it in bone corpuscle clumps, but the posterior pole was relatively free of pigmentation.

Retinal vessels were attenuated, and the disc normal. Goldmann fields showed an irregular constriction most severe in the upper visual fields. The ERGs were reduced to about half size, but there was no change of sensitivity (see Arden et al. $\left.{ }^{y}\right)$ and dark adapted rod thresholds (circles) were slightly elevated at the retinal locus tested. The elevation of cone flicker threshold is c. $0 \cdot 3 \mathrm{LU}$, which is considerably below the normal mean value.

polarise, the horizontal cell follows suit, the concentration of the inhibitory feedback transmitter declines, and the fractional change in transmitter caused by the same cone signal increases. In addition it is possible that the relationship between horizontal cell membrane potential change and the rate of liberation of feedback transmitter is optimised for the light adapted state. A given cone signal would then cause a maximal change in feedback transmitter

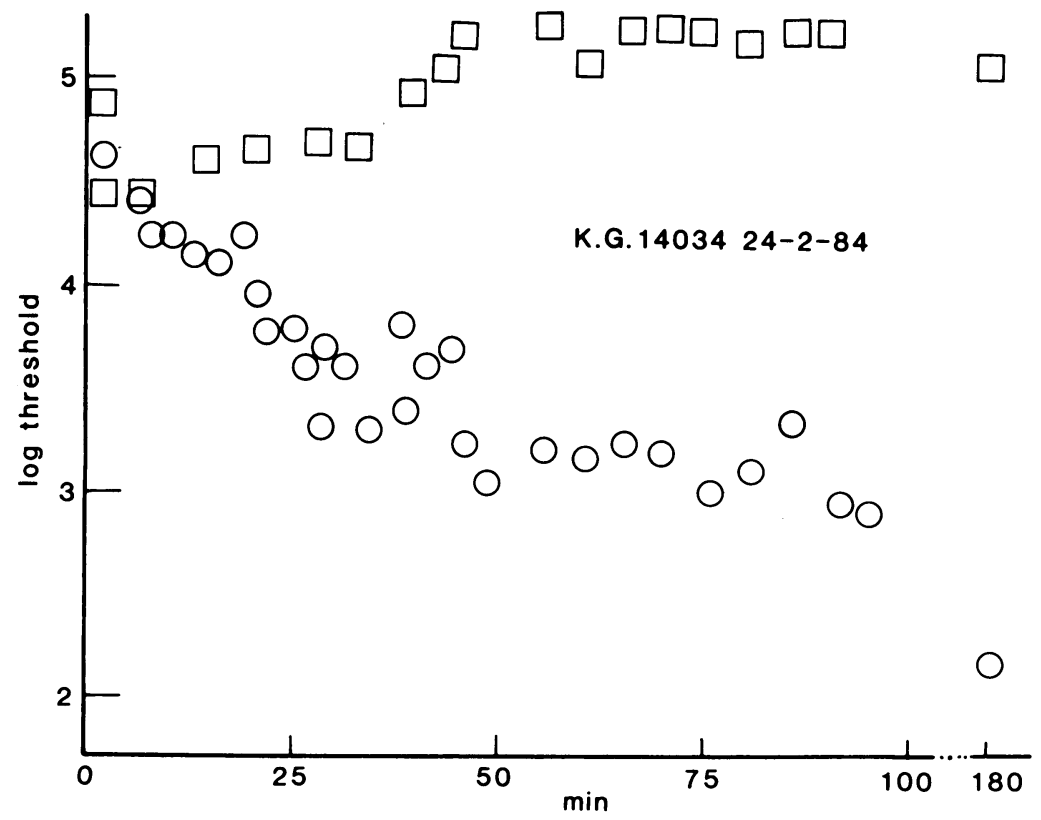

Fig. 10 Rod cone interaction in a patient with retinitis pigmentosa. This 24-year-old woman came from a family with autosomal dominant disease. When she was first seen the ERGs, fields, and rod thresholds were only slightly affected. In the few months before the test her condition had deteriorated, and the slow dark-adaptation curve shown was obtained. Note that after three hours the rod threshold (circles) was nearly normal. Cone flicker threshold (squares) rises after an unusual delay, but is quite pronounced. However, at the time of the rise the rods are extremely insensitive. 
output when the horizontal cell was partially hyperpolarised.

When the cone stimulus covers a large retinal area, it produces larger horizontal cell responses than when it subtends a small visual angle, and therefore the feedback may still be effective in the dark adapted eye. In the first few minutes after intense light adaptation, the rat rod receptor potential is maintained ${ }^{13}$ in the hyperpolarised state, but later the dark current returns once more along a time course that (in axolotl rods $^{32}$ ) approximates to, but is not identical with, that of the recovery of sensitivity to light, thus accounting for the attenuation of the cone flicker signal during rod dark adaptation.

Following intense bleaching there is a large afterhyperpolarisation in cat horizontal cells, which lasts for many seconds, but the time course of recovery may be faster than the rate of rhodopsin regeneration. ${ }^{25} 2633$ In turtle cones ${ }^{122}$ the horizontal cell feedback is best seen and operates between different classes of cones, but it has been reported ${ }^{5}$ that in man the interaction occurs only between rods and red cones; little is known about the feedback in mammalian or primate receptors. An alternative hypothesis is that the rods control the horizontal cell membrane potential indirectly, through an interplexiform cell feedback..$^{34}$

\section{CLINICAL IMPLICATIONS}

The appearance and magnitude of the rod-cone interaction described above would, on our hypothesis, depend upon the time and extent of the rod dark current. In those persons with exaggerated effects, perhaps the effectiveness of the rod transmitter in depolarising the horizontal cells is greater than normal. In our cases of X-linked schisis the reduction of the inhibition of cones by rods implies that the horizontal cell feedback must be reduced, but the relationship to pathological changes is not certain. In elderly persons cystic degeneration affects the outer retina, so that in the end a few bipolar cells mark the limits of the cysts, and it is entirely plausible that the lateral connections of horizontal cells are disrupted. In X-linked schisis the split is supposed to be in the nerve fibre layer or the inner plexiform layer. ${ }^{15}{ }^{35-37}$ However, the evidence is not conclusive, and the patients from whom the histological results were derived were not investigated by ERG, so it is not known if they were of the type we have seen. The lesions were much more severe than in our patients.

If the hypothesis advanced above is correct, this form of rod-cone interaction measures the integrity of the outer plexiform layer and also provides an index of the function of the rods which is independent of whether visual transduction occurs normally. Thus in retinitis pigmentosa we can show that in some cases, although there is a moderate reduction in sensitivity, the interaction is present. This would be consistent with the idea that there was a reduced rod dark current input to horizontal cells. In one case change in cone sensitivity is dissociated (Fig. 8) from the change in rod sensitivity, and hence on this argument dissociated from the rod membrane current. Therefore it is likely that in this patient the plasma membrane processes may be normal, while the intracellular mechanisms which control rod sensitivity are affected by the condition. Detailed analysis of selected patients is under way to determine whether reduction in membrane current and reduction of rhodopsin concentration run in parallel. This might answer the question whether rods in retinitis pigmentosa are shortened or disorganised.

We thank Dr T E Frumkes for a critical review of the manuscript, $\mathrm{Mr}$ A Bird and Drs K Kemp and W Ernst for helpful discussion and criticisms, and Mrs J Reid and Mr R Carter for technical assistance. The work was supported in part by an MRC project grant.

\section{References}

1 Enoch JM. Quantitative layer-by-layer perimetry. Invest Ophthalmol Visual Sci 1978; 17: 208-57.

2 Goldberg SH, Frumkes TE, Nygaard RW. Inhibitory influence of unstimulated rods in the human retina: evidence provided by examining cone flicker. Science 1983; 221: 180-1.

3 Lythgoe RJ, Tansley K. Reports of the Committee upon the Physiology of Vision. Medical Research Council Special Report Series 1929; 134: 72.

4 Arden GB, Hogg C. Absence of rod cone interaction in nyctalopia and retinoschisis. J Physiol (Lond) 1984; 353: 19P.

5 Colletta NJ, Adams AJ. Rod-cone interaction in flicker detection. Invest Ophthalmol Visual Sci 1983; 24 (ARVO suppl): 187.

6 Alexander KR, Fishman GA. Rod-cone interaction in flicker perimetry. BrJ Ophthalmol 1984; 68: 303-9.

7 Ernst W, Faulkner DJ, Hogg CR, Powell DJ, Arden GB, Vaegan. An automated static perimeter/adaptometer using light emitting diodes. BrJ Ophthalmol 1983; 67: 431-42.

8 Nygaard RW, Frumkes TE. LEDs: convenient inexpensive sources for visual experimentation. Vision Res 1982; 22: 435-40.

9 Arden GB, Carter RM, Hogg CR, et al. Rod and cone activity in patients with dominantly inherited retinitis pigmentosa: comparisons between psychophysical and electroretinographic measurements. BrJ Ophthalmol 1983; 67: 405-13.

10 Faulkner DJ. A new television visual stimulator for contrast sensitivity and evoked response testing. J Physiol (Lond) 1978; 275: 7P.

11 Ripps H. Nightblindness revisited: from man to molecules. Invest Ophthalmol Visual Sci 1982; 23: 588-609.

12 Baylor DA, Hodgkin AL. Detection and resolution of visual stimuli by turtle photoreceptors. J Physiol (Lond) 1973; 234: 163-98.

13 Hagins WA, Penn RD. Kinetics of the photocurrent of retinal rods. Biophys J 1972; 12: 1073-94.

14 Carr RE, Siegel IM. Ocular Electrodiagnosis. Baltimore: Williams and Wilkins, 1982.

15 Krill AE. Hereditary retinal and choroidal diseases. Hagerstown: Harper and Row, 1977: 2.

16 Duke-Elder S. A system of ophthalmology. London: Chapman and Hall, 1964: 3 (2).

17 Kelsey JH, Arden GB. Acquired unilateral loss of dark adaptation. Br J Ophthalmol 1971; 55: 38-43. 
18 Thaler A, Heilig R, Slozak H. Elektroretinogram und Elektrooculogram bei juvenile Retinoschisis. Klin Monatsbl Augenheilkd 1973; 163: 699-703.

19 Massof RW, Finklestein D. Rod sensitivity relative to cone sensitivity in retinitis pigmentosa. Invest Ophthalmol Vis Sci 1979; 18: 263-72.

20 Alexander KR, Fishman GA. Prolonged dark adaptation in patients with retinitis pigmentosa. $\mathrm{Br} J$ Ophthalmol in press.

21 Nelson E, Kolb H, Famiglietti EV Jr, Gouras P. Neural responses in the rod and cone systems of the cat retina: intracellular records and procion stains. Invest Ophthalmol Visual Sci 1976; 15: 946-53.

22 Baylor DA, Fuortes MGF, O'Bryan PM. Receptive fields of cones in the retina of the turtle. J Physiol (Lond) 1971; 214: 265-94.

23 Simon EJ. Two types of luminosity horizontal cells in the retina of the turtle. J Physiol (Lond) 1973; 230: 191-211.

24 Lamb TD. Spatial properties of horizontal cell responses in the turtle retina. J Physiol (Lond) 1976; 263: 239-55.

25 Steinberg RH. Rod and cone contributions to s-potentials from the cat retina. Vision Res 1969; 9: 1319-29.

26 Steinberg RH. Rod-cone interaction in s-potentials from the cat retina. Vision Res 1969; 9: 1331-44.

27 Niemeyer G, Gouras P. Rod and cone signals in s-potentials of the isolated perfused cat eye. Vision Res $1973 ; 13: 1603-12$.

28 Nelson $R$. Cat cones have rod input: a comparison of the response properties of cones and horizontal cell bodies in the retina of the cat. J Comp Neurol 1977; 172: 109-35.

29 Fuortes MGF, Schwartz EA, Simon EJ. Colour-dependence of cone responses in the turtle retina. J Physiol (Lond) 1973; 234: 199-216.

30 Naka K, Sakuranaga M, Chappell RL. Wiener analysis of turtle horizontal cells. Biomed Res 1982; 3 (suppl): 131-5.

31 Lassater EM, Lam DMK. The identification and some functions of GABAergic neurons in the distal catfish retina. Vision Res 1984; 24 : 497-506.

32 Ernst W, Kemp CM, Lake N. Studies on the effects of bleaching amphibian rod pigments. IV. Photoresponses recorded intracellularly from axolotl red rods following bleaching flashes. Exp Eye Res 1978; 27: 117-27.

33 Steinberg RH. The rod after effect in s-potentials from the cat retina. Vision Res 1969; 9: 1345-55.

34 Dowling JE, Ehinger B, Hedden WL. The interplexiform cell: a new type of retinal neuron. Invest Ophthalmol Visual Sci 1976; 15: 916-26.

35 Zimmerman LE, Spencer WH. The pathologic anatomy of retinoschisis with a report on two cases diagnosed as malignant melanoma. Arch Ophthalmol 1960; 63: 10-9.

36 Yanoff M, Rahn EH, Zimmerman LE. Histopathology of juvenile retinoschisis. Arch Ophthalmol 1969; 79: 49-53.

37 Manschot WA. Pathology of hereditary juvenile retinoschisis. Arch Ophthalmol 1972; 88: 131-8. 